\title{
Mastocitoma canino: aplicação do escore de Patnaik et al. para o diagnóstico/prognóstico de rotina
}

\section{Canine mastocytoma: application of Patnaik et al. escore for the routine diagnosis/prognosis}

\author{
Rogério Tortelly, ${ }^{\star}$ Eulógio Carlos Queiroz de Carvalho," Adriana V. Siciliano**
}

\begin{abstract}
Resumo
O diagnóstico clínico-laboratorial, diferencial dos mastocitomas com outras neoplasias do grupo de "tumores de células redondas cutâneos do cão" (histiocitoma cutâneo canino, tumor venéreo transmissível - extragenital, linfossarcoma cutâneo canino, plasmocitoma cutâneo canino - extramedular), assim como sua gradação morfológica em graus crescentes (I, II e III) de malignidade, conforme proposta de Patnaik et al. (1984), são importantes para efeitos prognósticos e terapêuticos. Foram estudadas 23 amostras de mastocitoma canino, a partir de peças cirúrgicas, necropsias e amostras de tecido/pele provindos de biópsia. Os resultados enquadrados (1 no grau I, 9 no grau II e 13 no III), foram discutidos e o escore empregado foi considerado de valor para a rotina de diagnóstico anatomopatológico em veterinária.
\end{abstract}

Palavras-chave: mastocitoma; canino; dermatopatologia; escore.

\begin{abstract}
The differential clinic-laboratorial diagnosis of the mastocytomas with other neoplasias of the group of "cutaneous tumors of round cells of the dog"(canine cutaneous histiocytoma, transmissible venereal tumor - extragenital, canine cutaneous linfossarcoma, canine cutaneous plasmacytomas - extramedular), as well as its morphologic gradation in growing degrees (I, II and III) of malignancy, according to proposal of Patnaik et al., (1984), they are important for effects prognostics and therapeutic. They went you study 23 samples of canine mastocytoma, starting from surgical pieces, necropsias and samples for biopsy. The framed results ( 1 in the degree I, 9 in the degree II and 13 in III), they were discussed and the score employee was considered of value for the routine of phatologycal diagnosis in veterinary.
\end{abstract}

Keywords: mastocytoma; canine; dermatopathology; score.

\section{Introdução}

Mastocitomas são neoplasias constituídas de mastócitos, descritas pela primeira vez por Bashford et al. em 1905, apresentando uma enorme variabilidade clínica e biológica (Tardy et al., 1992). São comuns em caninos, mas acometem também felinos, bovinos, eqüinos e suínos (Jarret e Mackey, 1974).

A grande maioria dos mastocitomas caninos primários se origina na derme e subcutâneo, representando 7 a $21 \%$ de todos os tumores de pele na espécie (Dean, 1988) e 11 a $21 \%$ dentre as variantes cutâneas malignas. Os linfonodos regionais são os sítios mais comuns de metástases (Rogers, 1993). Cerca de $45 \%$ dos casos ocorrem nos membros pélvicos, períneo e genitália externa (Muller e Kirk, 1976), sendo a maior freqüência verificada na metade caudal do corpo (Dean, 1988) e após o sexto ano de vida (Kleiner et al., 1988). Estão entre as neoplasias mais comuns em caninos, com uma freqüência de $6 \%$ em relação às demais (Stannard e Pulley, 1978).
Os mastocitomas, como parte do grupo de "tumores de células redondas cutâneas do cão", merecem diagnóstico diferencial com os demais: histiocitoma cutâneo canino, linfossarcoma cutâneo do cão, tumor venéreo transmissível (variante cutânea) e plasmocitoma cutâneo - extramedular (Gross et al., 1992; Tardy et al., 1992).

Podem se apresentar como nódulos solitários ou, mais raramente, múltiplos, de tamanhos variados, circunscritos ou com bordas mal definidas, de consistência amolecida ou firme, ocasionalmente, ulcerados e com edema e/ou eritema ao redor (Thomsom, 1990; Willemse, 1994).

Fenômenos paraneoplásicos associados aos mastocitomas podem ser atribuídos à degranulação dos mastócitos. A excessiva liberação de histamina pode resultar em úlcera gástrica e duodenal, quando esta se liga aos receptores $\mathrm{H} 2$ e leva as células parietais da mucosa gástrica a produzirem mais ácido clorídrico, e ainda, aumentando a motilidade gástrica. A ação histamínica, aumentando a permeabilidade vascular, pode levar à trombose e conseqüente necrose isquêmica da mucosa (Rogers, 1993).

\footnotetext{
* Docentes do Serviço de Anatomia Patológica Veterinária/UFF, Prof. Jefferson Andrade dos Santos (SAPVJAS). Rua Vital Brazil Filho, 64, Vital Brazil - Niterói, RJ - CEP 24230-340 - Tel.: (21) 714-8454 - Fax: (21) 714-4041.

** Graduada em Medicina Veterinária/UFF, ex-estagiária do SAPVJAS.
} 
Retardo cicatricial com deiscência de pontos tem sido associado à liberação de enzimas proteolíticas e aminas vasoativas dos grânulos dos mastócitos (Tardy et al., 1992), assim como vem sendo sugerido que a histamina possa lisar receptores $\mathrm{H} 1$ e $\mathrm{H} 2$ dos macrófagos, resultando na liberação de fator supressor fibroblástico, que diminuiria a fibroplasia normal e retardaria a cicatrização.

Episódios de choque hipovolêmico são achados incomuns em cães, mas quando de sua ocorrência, podem ser conseqüentes da liberação excessiva de histamina e, possivelmente, prostaglandinas, em casos de mastocitomas (Tardy et al., 1992).

A citopatologia de decalques da superfície de corte do tumor pode, com freqüência, oferecer um diagnóstico precoce, no mínimo, presuntivo (Muller e Kirk, 1976).

Considerando as variações histológicas e do comportamento biológico dos mastocitomas, Patnaik et al. (1984) criaram um escore e propuseram sua adoção, com base na morfologia nuclear, número de figuras de mitose, pleomorfismo celular, presença e quantidade de grânulos. Esse escore divide os mastocitomas em: grau I (bem diferenciados), grau II (intermediários) e grau III (anaplásicos ou indiferenciados).

Estudos para a aplicação do mesmo escore em gatos não revelaram uma correlação anátomo-clínica significativa (Molander-McCrary et al., 1998).

O diagnóstico diferencial dos mastocitomas com outras neoplasias do grupo dos "tumores de células redondas cutâneas do cão", assim como a sua gradação, são importantes para efeitos prognósticos e terapêuticos. Valerá a presente publicação para a valorização, o exercício e a consolidação do escore de Patnaik et al. (1984) na rotina de diagnóstico anatomopatológico.

\section{Material e métodos}

Amostras dos 23 casos de mastocitoma cutâneo em cães, provindas de animais sem distinção racial, de idade ou sexo, foram colhidas de peças cirúrgicas, de necropsias e para biópsias, na rotina do Serviço Prof. Jefferson Andrade dos Santos de Patologia Veterinária da UFF. Estas foram processadas por inclusão em parafina e coradas pelos HE e Giemsa.

\section{Resultados e discussão}

Os 23 casos, submetidos ao HE e Giemsa, tiveram a seguinte distribuição no escore de Patnaik et al. (1984):

Grau I: 1 caso, por apresentar mastócitos uniformes, dispostos em cordões ou, raramente, em ninhos imersos em colágeno abundante. Os citoplasmas eram granulados, amplos e ovais. Os eosinófilos tendiam à situação perivascular e as figuras de mitose eram escassas (Figura 1).

Grau II: 9 casos, por mostrarem células arredondadas, de dimensões variadas, com granulação de moderada a acentuada e, algumas vezes, gigantes, mono ou binucleadas e de citoplasmas acidófilos. Os eosinófilos infiltravam-se em número moderado a acentuado. O colágeno se mostrava desintegrado e as mitoses eram raras (Figuras 2 e 3).

Grau III: 13 casos exibiram células gigantes, mono ou multinucleadas, com núcleos de dimensões variadas e polimórficos. A granulação citoplasmática e o número de eosinófilos eram variados, tendendo para discretos. As figuras

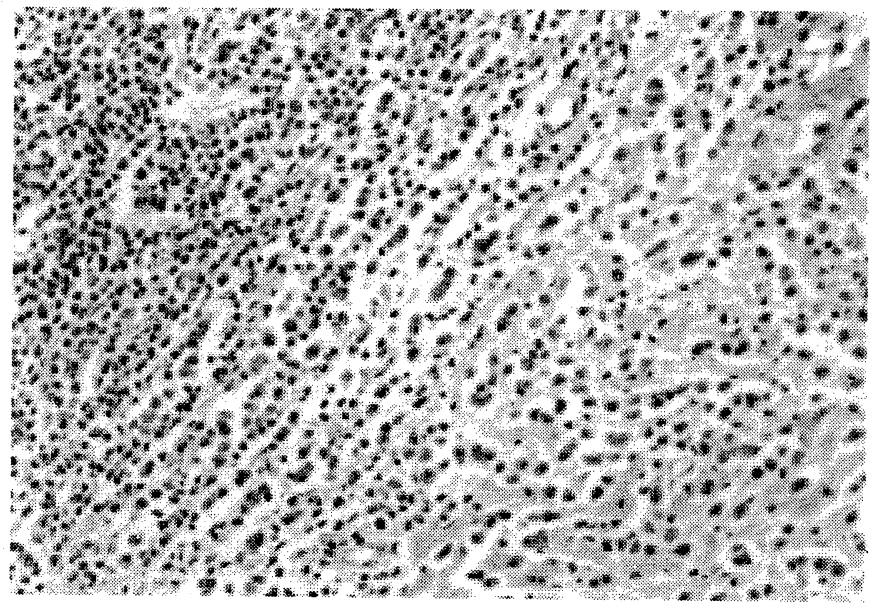

Figura 1: Mastocitoma cutâneo canino 1: Mastócitos com fina granulação citoplasmática, dispostos em cordões imersos em abundante colágeno, ao lado de infiltrado de eosinófilos. HxE, Obj.:20

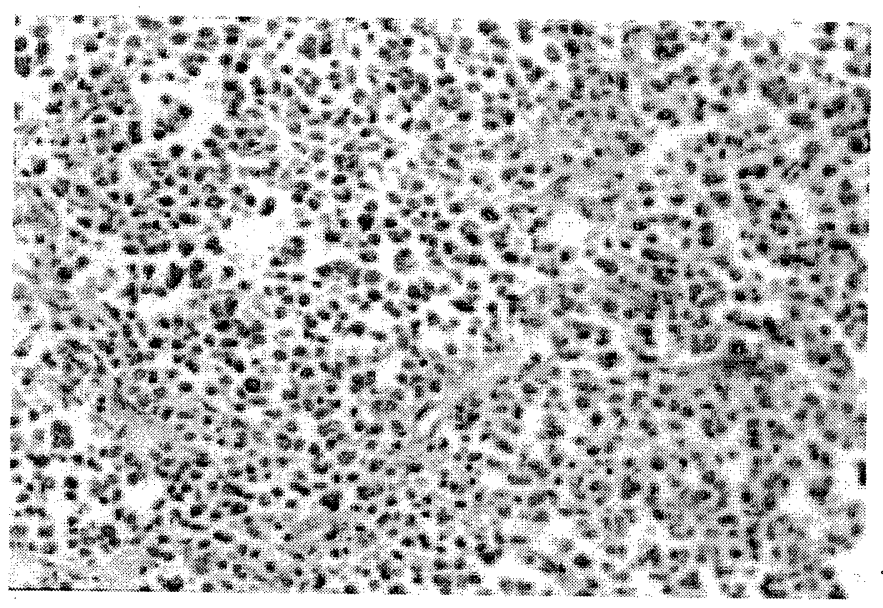

Figura 2: Mastocitoma cutâneo canino II: Mastócitos de dimensões variadas, mono e binucleados, com acidofilia citoplasmática e algumas figuras de mitose. HxE, Obj.: 20

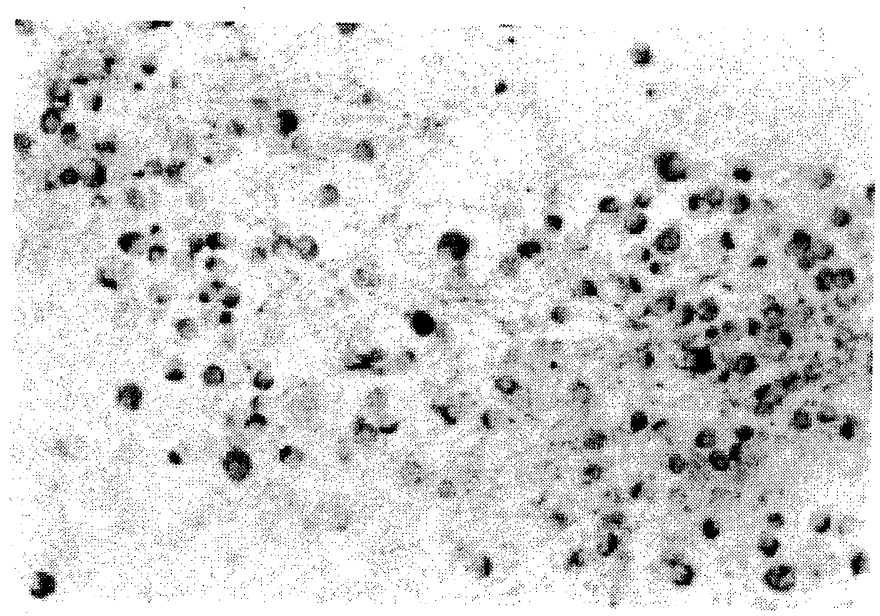

Figura 3: Mastocitoma cutâneo canino II: Metacromasia de granulação citoplasmática. Giemsa, Obj.: 40 
de mitose eram escassas, mas podiam ser anômalas. Havia sinais de necrose e reação inflamatória aguda (Figura 4).

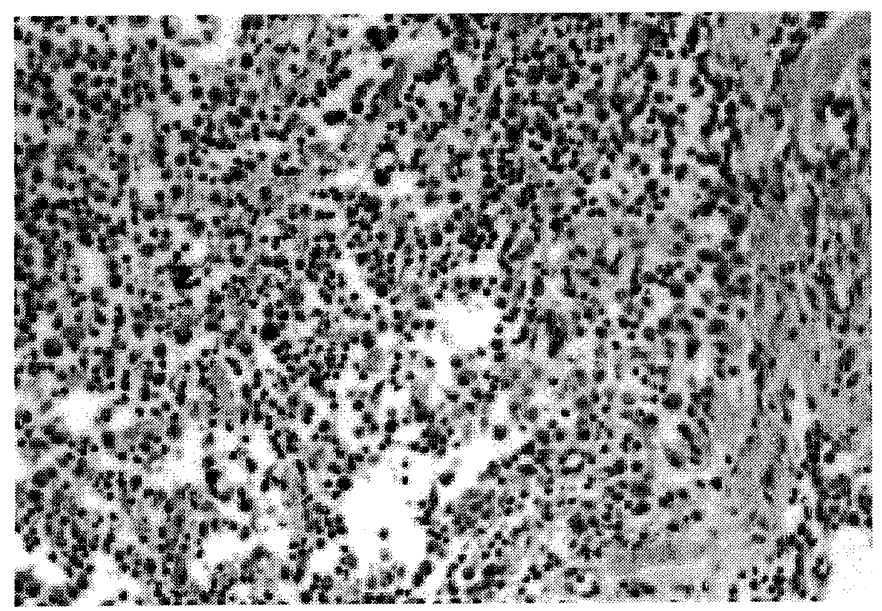

Figura 4: Mastocitoma cutâneo canino III: Mastócitos polimórficos e, alguns poucos, com acidofilia citoplasmática e infiltrado de eosinófilos associado a edema (inflamatório), HxE, Obj.: 20.

\section{Referências bibliográficas}

DEAN, P. W. Mast Cell Tumors in Dog: Diagnosis, Treatment and Prognosis. Veterinary Medicine. v. 83. p. 185-192, 1988.

GROSS, T. L.; IHRKE, P. J.; WALDER, E. J. Veterinary Dermatopathology: a macroscopic and microscopic evaluation of canine and feline skin disease. St. Louis: Mosby, 1992.

JARRET, W. F. H. \& MACKEY, L. J. Neoplastic Diseases of the Haematopoietic and Limphoid Tissues. Bulletin of the World Health Organization. v. 50, p. 34, 1974.

KLEINER, J. N. et al. Mastocitomas em cães e gatos. Revista do Setor de Ciências Agrárias. v.10, p. 227-229, 1988.

MOLANDER-MCCRARY, H., HENRY, C. J., POTTER, K., TYLER, J. W., BUSS. M. S. Cutaneous Mast Cell Tumors in Cats: 32 cases (19911994). Journal of the American Animal Hospital Association. v. 34, Jul./Aug./1998, p. 281-284.

MULLER, G. H. \& KIRK, R. W. Small Animal Dermatology. 2. ed. Estados Unidos: W. B. Saunders Company, 1976. Cap. 86: Mastocytoma. p. 658-662.
Houve uma sensivel diferença histológica entre os achados nos graus I e II, revelada pelas definições dos limites e da uniformidade celular e nuclear, além da grande quantidade de colágeno e das raras figuras de mitose observadas no grau I.

Entretanto, entre os graus II e III havia, em vários parâmetros, alguma similaridade morfológica, o que dificultava a gradação no escore e obrigava ao corte seriado ou resseriado. Preponderaram no grau III o elevado número de células gigantes e acidófilas, o polimorfismo, a policariose e as figuras de mitose, às vezes, anômalas. $O$ caráter invasivo, a necrose e o edema foram achados freqüentes neste grau.

O infiltrado de eosinófilos não contribuiu para a classificação. Já o parâmetro da granulação citoplasmática revelou-se bastante subjetivo.

No diagnóstico anatomopatológico em geral, os critérios pessoais do patologista, assim como a subjetividade de alguns parâmetros, como nos mastocitomas, apontam para a necessidade da adoção de padrões diagnósticos definidos que melhor orientem este importante apoio clínico.

PATNAIK, A. K.; EHLER, W. J.; MacEWEN, E. G. Canine Cutaneous Mast Cell Tumor: morphologic grading and survival time in 83 dogs. Veterinary Pathology. v. 27, p. 469-474, 1984.

ROGERS, K. S. Common Questions About Diagnosing and Treatment Canine Mast Cell Tumors. Veterinary Medicine. v. 88, p. 246-250, 1993.

STANNARD, A. A. e PULLEY, L. T. Mastocytoma of the Dog. In MOULTON, J. E. Tumors in Domestic Animals. 2. ed. California: University of California Press, 1978. Cap. 2: Tumors of the Skin an Soft Tissues. p. 26-30.

TARDY, S. et al. Canine Mast Cell Tumor: clinical, therapeutic and comparative features. European Journal of Campanion Animal Practice. v. 3, p. 21-33, 1993.

THOMSON, R. G. Patologia veterinária especial. São Paulo: Manole, 1990.

WILLENSE, T. Dermatologia Clínica de Cães e Gatos: guia para o dignóstico e terapia. São Paulo: Manole, 1994. Cap. 13: Doenças Neoplásicas. p. 110-112. 